\title{
Replaced right hepatic artery and its segmental distribution
}

\author{
Orhan Beger, Özlem Elvan, Zeliha Kurtoğlu \\ Department of Anatomy, Faculty of Medicine, Mersin University, Mersin, Turkey
}

\begin{abstract}
A case of replaced right hepatic artery arising from the superior mesenteric artery is presented with its segmental distribution and the morphometric features. The case was encountered in a 66-year-old formalin-fixed male cadaver during dissection for undergraduate lab education. Length and diameter of the replaced right hepatic artery were measured $63.10 \mathrm{~mm}$ and $3.6 \mathrm{~mm}$, respectively. The replaced right hepatic artery coursed posterior to the portal vein initially, and then lateral to it. One of its branches entered into liver segments V and VIII, and the other entered into segments VI and VII. Left hepatic artery arose from the common hepatic artery and gave the middle hepatic artery $11.9 \mathrm{~mm}$ distal to its origin. Length and diameter of the middle hepatic artery were measured $30.2 \mathrm{~mm}$ and $1.2 \mathrm{~mm}$, respectively. After giving a small branch to caudate lobe, the middle hepatic artery reached the quadrate lobe. The diameter and segmental distribution of replaced right hepatic artery was similar to the normal right hepatic artery described in earlier studies. The middle hepatic artery arose from the left hepatic artery at a substantial distance from the liver tissue in the presence of a replaced right hepatic artery. This is of clinical significance in liver transplantations as the arterial supply of segment IV is from the middle segmental artery.
\end{abstract}

Keywords: liver; liver transplantation; replaced right hepatic artery; segmental distribution

Anatomy 2015;9(3):185-188 @2015 Turkish Society of Anatomy and Clinical Anatomy (TSACA)

\section{Introduction}

Two major types of variant hepatic arteries have been described in the literature: replaced and aberrant (or accessory). Replaced hepatic artery has a different origin from the proper hepatic artery and supplies the lobe of liver by itself. Accessory hepatic artery is present in addition to the main artery of the lobe. ${ }^{[1]}$

Hepatic arteries are known to have many variations in terms of origin. Koops et al. ${ }^{[2]}$ stated that the replaced hepatic artery was first described in 1756 by Haller. Data provided from liver transplantations, angiographies and cadaveric dissections have become of use for identification of hepatic artery variations. ${ }^{[2]}$ Two basic classifications are found in literature regarding variant hepatic arteries. First classification was by Michels ${ }^{[3]}$ based on his results from 200 cadaveric dissections. The other was by Hiatt et al. ${ }^{[4]}$ who studied the records of 1000 patients with liver transplantation and reported the incidence of the replaced hepatic arteries without consideration of their origin.
Vascular supply pattern of the segments of the liver has critical importance in liver transplantation. ${ }^{[5]}$ The distribution of the hepatic arteries can be comprehended by knowing the segmental structure of the liver. According to Bismuth, ${ }^{[6]}$ right and left liver lobes are separated from each other by the middle hepatic vein. In the right lobe, right hepatic vein divides the anterior and posterior segments vertically, while portal vein divides the superior and inferior segments transversely. In the left lobe, the vertical line between the medial and lateral segments is the umbilical fissure. One of the transverse lines, the left portal vein separates the medial segments, and the other transverse line, left hepatic vein, separates the lateral segments. The borders of the caudate lobe are the inferior vena cava medially, and the venous ligament laterally. Segmental distribution pattern of normal hepatic arteries are well known. The right hepatic artery (RHA) supplies the four segments (segments V-VIII) of the right lobe. The left hepatic artery (LHA) supplies the lateral superior and lateral inferior (II, III) segments. The middle hepatic artery (MHA) supplies the medial superior and medial inferior 


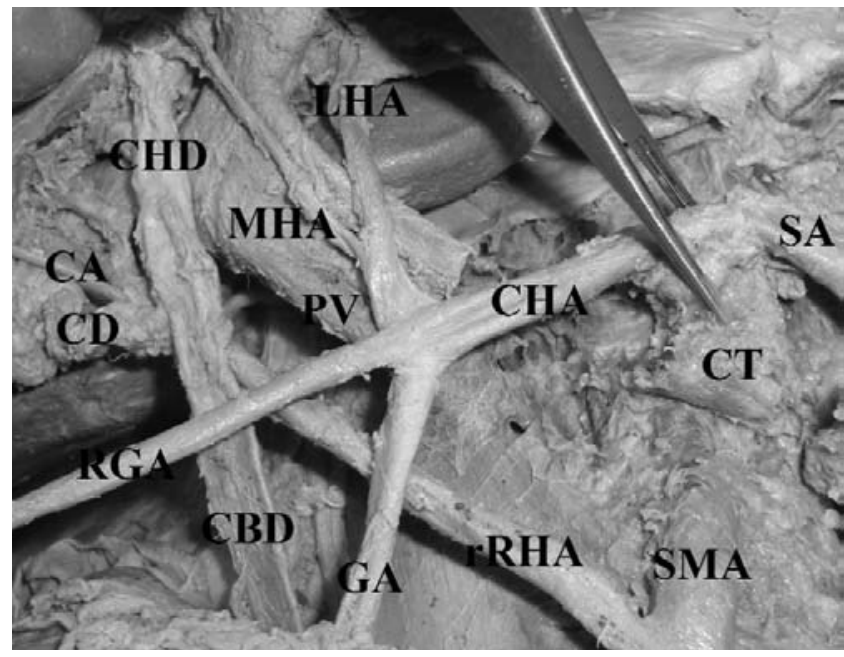

Figure 1. Replaced right hepatic artery ( $\mathrm{rHH}$ ) arising from the superior mesenteric artery. Celiac trunk was retracted upwards. CA: cystic artery; CBD: common bile duct; CD: cystic duct; CHA: common hepatic artery; CHD: common hepatic duct; CT: celiac trunk; GA: gastroduodenal artery; LHA: left hepatic artery; MHA: middle hepatic artery; PV: portal vein; RGA: right gastric artery; SA: splenic artery; SMA: superior mesenteric artery.

(IV) segments. Caudate lobe (segment I) is supplied by both RHA and LHA ${ }^{[6]}$ However, segmental distribution of the replaced and accessory hepatic arteries have not been sufficiently studied.

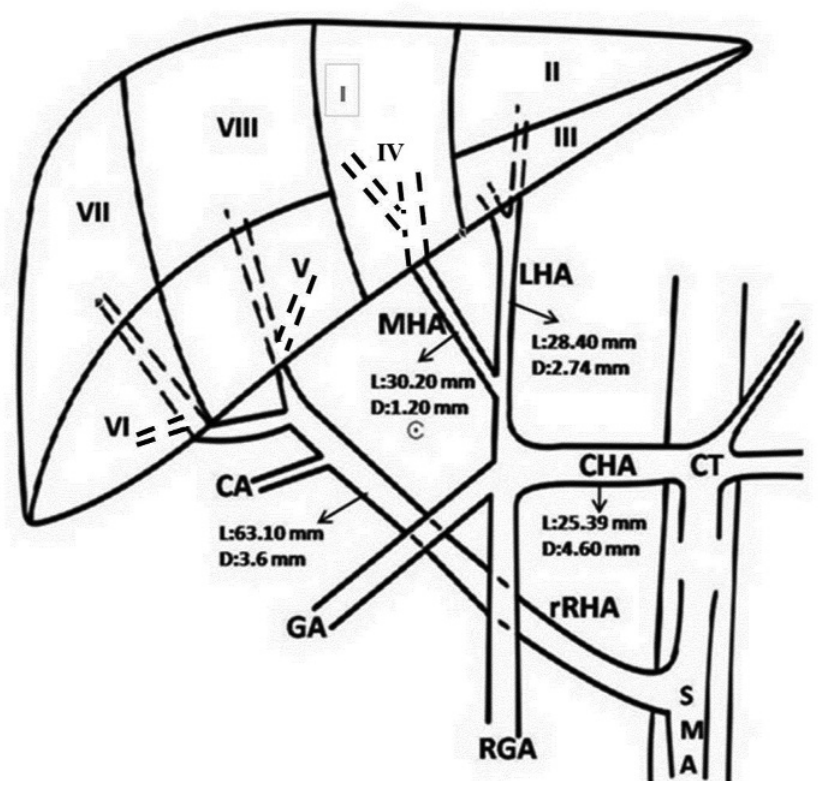

Figure 2. Segmental distribution of hepatic arteries. I-VIII: Segments I-VIII of liver; CA: cystic artery; CHA: common hepatic artery; CT: celiac trunk; GA: gastroduodenal artery; LHA: left hepatic artery; MHA: middle hepatic artery; RGA: right gastric artery; rRHA: replaced right hepatic artery; SMA: superior mesenteric artery.
The diameter and length of variant hepatic arteries may be different from that of normal hepatic arteries. These features are important in liver transplantations and catheter insertion for chemotherapeutic drugs in treatment of liver tumors. ${ }^{[7-9]}$

In this report, we investigated the course, external diameter and segmental distribution of hepatic arteries in a case with replaced right hepatic artery (rRHA) arising from the superior mesenteric artery (SMA).

\section{Case Report}

During dissection of a 66-year-old formalin-fixed male cadaver for undergraduate medical education, a RHA arising from SMA was encountered (Figures $\mathbf{1}$ and 2). This is defined as "replaced right hepatic artery" (rRHA) in the literature ${ }^{[1]} \mathrm{rRHA}$ was arising $22.4 \mathrm{~mm}$ distal to the beginning of SMA. During its course toward the right lobe of liver, rRHA was initially posterior to the portal vein, and then lateral to it. The length and mid-portion diameter of rRHA were measured as $63.1 \mathrm{~mm}$ and $3.6 \mathrm{~mm}$, respectively. It gave cystic artery in Calot's triangle, and then divided into two branches. One of these branches entered into segments V and VIII, while the other entered into segments VI and VII. Common hepatic artery (CHA) originated from the celiac trunk (CT). Its length and mid-portion diameter were measured $25.39 \mathrm{~mm}$ and $4.6 \mathrm{~mm}$, respectively. Coursing anterior to portal vein, $\mathrm{CHA}$ gave the LHA, gastroduodenal and right gastric artery branches. LHA arose from the CHA with a diameter of $2.74 \mathrm{~mm}$, and coursed anterior to the portal vein and gave the MHA $11.9 \mathrm{~mm}$ distal to the origin and, after coursing for 28.4 $\mathrm{mm}$, ramified into two terminal branches. The diameter of LHA was measured as $2.6 \mathrm{~mm}$ in the distal part. The terminal branches entered into segments II and III in the left lobe. The length and diameter of the MHA were $30.2 \mathrm{~mm}$ and $1.2 \mathrm{~mm}$, respectively. MHA coursed through the umbilical fissure, and after giving a small branch to caudate lobe, it reached to the quadrate lobe.

\section{Discussion}

One of the most important CHA variations is rRHA arising from SMA. ${ }^{[2-4,10]}$ The case has been identified as Type 3 in classifications of Michels ${ }^{[3]}$ and Hiatt et al. ${ }^{[4]}$ According to data obtained from dissection studies, liver transplantations and angiographies, the incidence of rRHA varies between $3.5-18 \% .^{[2]}$

Deviations from the normal pattern of embryological development constitute the cause of arterial variations. The hepatic, splenic and the left gastric arteries originate from the longitudinal anastomosis between the first and fourth roots of omphalomesenteric artery. While CT and 
its branches exit from this anastomosis, SMA exits from the fourth root which is located at the bottom of the anastomosis. If this separation occurs at the upper part of the anastomosis, one branch of CT may originate from SMA. ${ }^{[1,12]}$ The hepatic arteries are visible in the hepatic hilum at the 8th and then within the liver parenchyma at the 10th gestational weeks. ${ }^{[13]}$ Intrahepatic arterial circulation is related to portal and biliary systems. ${ }^{[13]}$ The vascular development and differentiation affect not only variation, but also organogenesis. During the morphogenesis phase, the liver develops from the hepatic bud in the mesenchyme of the transverse septum and from the parenchymal cells within the developing vascular system. ${ }^{[14]}$ Thus, it can be assumed that variations of the extrahepatic arteries may accompany variations of the segmental distribution of intrahepatic arteries. Salbacak et al., ${ }^{[15]}$ in their dissection on 20 fixed cadavers, stated that the intrahepatic distribution of proper hepatic artery varied in $46.66 \%$. However, no variations in segmental distribution of intrahepatic artery were observed in our case.

The arterial supply of segment IV has critical importance in liver transplantation for safety of the donor. Jin et al. ${ }^{[5]}$ reported that the right lobe resected donors might have an infarction in the quadrate lobe if the artery of segment IV originates from RHA. The MHA supplies segment of $I V \cdot{ }^{[16]}$ With these taken into consideration, the origin of MHA seems to be very important for clinical practice.

Wang et al. ${ }^{[11]}$ defined the MHA as an artery branching at the hilum of liver and then coursing in the umbilical fissure. They stated that MHA could originate from the RHA in the presence of a replaced LHA, and from the LHA in the presence of rRHA as in our case. However, Jin et al. ${ }^{[5]}$ indicated that MHA may have an origin from outside of the hilum. They stated that this artery arises from the proximal part of RHA, but not that of LHA. ${ }^{[5]}$ However, another study by Ghosh ${ }^{[16]}$ showed that MHA

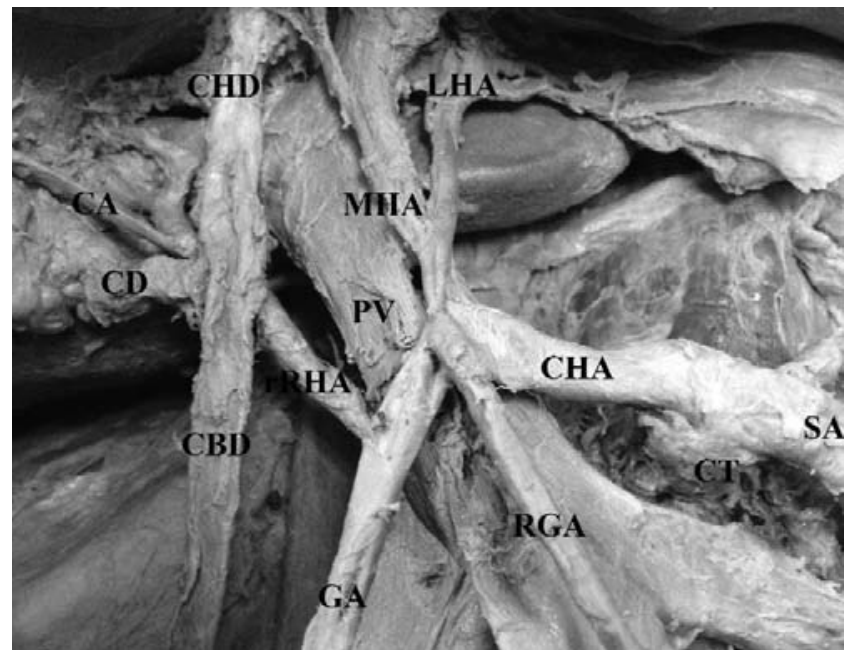

Figure 3. Relationship between the variant hepatic artery and portal vein. Celiac trunk was retracted upwards. CA: cystic artery; CBD: common bile duct; CD: cystic duct; CHA: common hepatic artery; CHD: common hepatic duct; CT: celiac trunc; GA: gastroduodenal artery; LHA: left hepatic artery; MHA: middle hepatic artery; PV: portal vein; RGA: right gastric artery; rRHA: replaced right hepatic artery; SA: splenic artery.

can also originate from the proximal part of LHA. We did not find any report similar to our case in which the MHA arose from the proximal part of the LHA (with a distance of $28.4 \mathrm{~mm}$ to the liver) in the presence of a rRHA.

In this case, rRHA coursed first posterior to the portal vein, and then as it reached higher lateral to it (Figure 3). Sureka et al. ${ }^{[17]}$ reported that complications of surgery such as bleeding would be eliminated by acknowledging the relationship of rRHA with the portal vein.

There are inconsistent reports in the literature for the diameters of variant and normal hepatic arteries (Table 1). Silveira et al ${ }^{[0]}$ studied the external diameters of variant and normal hepatic arteries, and suggested that measurements from fixed cadavers were similar to fresh cadaver or

Table 1

Diameters and statistical comparison of normal and variant hepatic arteries described in the literature studies ( $\mathrm{mm}$ ).

\begin{tabular}{|c|c|c|c|c|c|}
\hline Reference & Material & $\mathbf{n}$ & $\begin{array}{c}\text { Artery } \\
\text { diameter }(\mathrm{mm}) \pm(\mathrm{SD})\end{array}$ & Normal / variant artery & $\mathbf{p}$ \\
\hline \multirow[t]{4}{*}{ Silveira et al. $(2009)^{[9]}$} & Cadaver & 21 & $\mathrm{CHA}^{*}$ & $5 \pm 0.4 / 5.2 \pm 0.5$ & $p>0.05$ \\
\hline & & & $\mathrm{PHA}^{*}$ & $4.5 \pm 0.3 / 3.8 \pm 0.1$ & $p>0.05$ \\
\hline & & & $\mathrm{LHA}^{*}$ & $3 \pm 0.3 / 2.8 \pm 0.3$ & $p>0.05$ \\
\hline & & & $\mathrm{RHA}^{*}$ & $3.6 \pm 0.4 / 3.2 \pm 0.3$ & $p>0.05$ \\
\hline Sakamoto et al. $(2002)^{[8]}$ & Angiography & 101 & $\mathrm{LHA}^{\dagger}$ & $2 \pm 0.8 / 2.5 \pm 0.7$ & $p=0.03$ \\
\hline
\end{tabular}

${ }^{*}$ external diameter; ${ }^{+}$: internal diameter; CHA: common hepatic artery; LHA: left hepatic artery; PHA: proper hepatic artery; RHA: right hepatic artery. 
in vivo measurements. Although they stated that the diameter of the variant hepatic artery was narrower than the normal hepatic artery, this difference was not statistically significant. ${ }^{[9]}$ Silveira et al. ${ }^{[9]}$ concluded that the internal diameters of the proper hepatic artery and CHA must be wider than $3 \mathrm{~mm}$, regardless of a variant artery presence. They also suggested that donors with an internal artery diameter between 2 and $3 \mathrm{~mm}$ must be partially, and donors with arteries smaller than $2 \mathrm{~mm}$ internal diameter completely ignored in liver transplantations, on account of the risk for hepatic artery thrombosis. Ishigami et al. ${ }^{[7]}$ found the internal diameter of variant CHA significantly smaller than the internal diameter of normal CHA, and emphasized that donors with a variant hepatic artery had high risk of thrombosis and stenosis in the postoperative period. Based on their investigation on angiographies of left-sided liver grafts from 101 living donors, Sakamato et al. ${ }^{[8]}$ found the aberrant LHA wider and longer than the normal LHA. They suggested that this condition may be an advantage in terms of anastomosing in liver transplantations ${ }^{\left[{ }^{[8]}\right.}$ Although diameter of variant hepatic artery is very important for liver transplantations and selection of catheters in treatments of liver tumors, current data on its diameter is insufficient and more studies are needed.

\section{Conclusion}

The diameter, length, course and segmental distribution of the hepatic artery is of utmost importance during surgical and invasive approaches to the liver. rRHA arising from SMA may not be uncommon to encounter in clinical practice due to its high incidence. Therefore, it is important to identify the variant artery, its size and intrahepatic segmental distribution. In the present case with rRHA, MHA arising from the LHA at a substantial distance from the liver tissue was remarkable, due to its implications in liver transplantation.

\section{References}

1. Wang S, He X, Li Z, Peng Z, Tam NL, Sun C, Hu A, Huang J. Characterization of the middle hepatic artery and its relevance to living donor liver transplantation. Liver Transpl 2010;16:736-41.
2. Koops A, Wojciechowski B, Broering DC, Adam G, KrupskiBerdien G. Anatomic variations of the hepatic arteries in 604 selective celiac and superior mesenteric angiographies. Surg Radiol Anat 2004;26:239-44.

3. Michels NA. Newer anatomy of the liver and its variant blood supply and collateral circulation. Am J Surg 1966;112:337-47.

4. Hiatt JR, Gabbay J, Busuttil RW. Surgical anatomy of the hepatic arteries in 1000 cases. Ann Surg 1994;220:50-2.

5. Jin GY, Yu HC, Lim HS, Moon JI, Lee JH, Chung JW, Cho BH. Anatomical variations of the origin of the segment 4 hepatic artery and their clinical implications. Liver Transpl 2008;14:1180-4.

6. Bismuth H. Surgical anatomy and anatomical surgery of the liver. World J Surg 1982;6:3-9.

7. Ishigami K, Zhang Y, Rayhill S, Katz D, Stolpen A. Does variant hepatic artery anatomy in a liver transplant recipient increase the risk of hepatic artery complications after transplantation? AJR Am J Roentgenol 2004;183:1577-84.

8. Sakamoto Y, Takayama T, Nakatsuka T, Asato H, Sugawara Y, Sano $\mathrm{K}$, Imamura H, Kawarasaki H, Makuuchi M. Advantage in using living donors with aberrant hepatic artery for partial liver graft arterialization. Transplantation 2002;75:518-21.

9. Silveira LA, Silveira FB, Fazan VP. Arterial diameter of the celiac trunk and its branches: anatomical study. Acta Cir Bras 2009;24:43- 7 .

10. Jelev L, Angelov AK. A rare type of hepatobiliary arterial system in man-presence of accessory left and replaced right hepatic arteries and double cystic arteries. Anatomy 2015;9:100-3.

11. Wang BG, Fröber R. Accessory extrahepatic arteries: blood supply of a human liver by three arteries. A case report with brief literature review. Ann Anat 2009;191:477-84.

12. Cavdar S, Sehirli U, Pekin B. Celiacomesenteric trunk. Clin Anat 1997;10:231-4.

13. Collardeau-Frachon S, Scoazec JY. Vascular development and differentiation during human liver organogenesis. Anat Rec (Hoboken) 2008;291:614-27.

14. Hassan GMA, Sliem HA, Ellethy AT. Hepatic embryonic development and anomalies of the liver. J Gastroenterol Hepatol Res 2013;2: 489-93.

15. Salbacak A, Soylu R, Ziyla T, Şeker M, Duman S, Büyükmumcu M. İnsanlarda arteria hepatica propria'nın intrahepatik dağılımı ve karaciğerin subsegmentasyonu. Selçuk Üniversitesi Tip Fakültesi Dergisi 1989;5:71-80.

16. Ghosh SK. Variations in the origin of middle hepatic artery: a cadaveric study and implications for living donor liver transplantation. Anat Cell Biol 2014;47:188-95.

17. Sureka B, Mittal MK, Mittal A, Sinha M, Bhambri NK, Thukral BB. Variations of celiac axis, common hepatic artery and its branches in 600 patients. Indian J Radiol Imaging 2013;23:223-33.

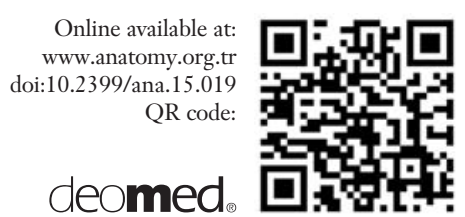

\author{
Correspondence to: Orhan Beger, MD \\ Department of Anatomy, Faculty of Medicine, \\ Mersin University, Ciftlikköy Campus, \\ Phone: +90 3243610683 / 1092 \\ e-mail: obeger@gmail.com \\ Conflict of interest statement: No conflicts declared.
}

This is an open access article distributed under the terms of the Creative Commons Attribution-NonCommercial-NoDerivs 3.0 Unported (CC BY-NCND3.0) Licence (http://creativecommons.org/licenses/by-nc-nd/3.0/) which permits unrestricted noncommercial use, distribution, and reproduction in any medium, provided the original work is properly cited. Please cite this article as: Beger O, Elvan Ö, Kurtoğlu Z. Replaced right hepatic artery and its segmental distribution. Anatomy 2015;9(3):185-188. 